\title{
Informações pedagógicas de cursos de psicología em sites de instituições de ensino superior
}

\section{Psychology programs' pedagogical data in websites of Brazilian higher education institutions}

\section{Gabriela Andrade da Silva' (1) \\ Caio Rudá2 (1) \\ Victória Dourado Martins ${ }^{3}$ (i) \\ João Paulo Leal Borges 4 (i) \\ João Pedro Rodrigues Alves 5 (1) \\ Tárcila Lorrane Fernandes de Sousa Soares ${ }^{6}$ (1)}

1'Autora para correspondência. Universidade Federal do Sul da Bahia. Teixeira de Freitas, Bahia, Brasil.gabriela.silva.ufsb@gmail.com 2-6Universidade Federal do Sul da Bahia (Teixeira de Freitas). Bahia, Brasil. caioruda.o@gmail.com, victoria-martins@outlook.com.br, joaopaulolb97@gmail.com, joaopedro.alves@cja.ufsb.edu.br, tarcilafernandes97@gmail.com

\begin{abstract}
RESUMO | Nos últimos 30 anos, o ensino superior brasileiro cresceu vertiginosamente, e cursos de Psicologia apresentaram um dos maiores crescimentos de matrículas. Este artigo objetivou analisar a disponibilidade on-line de informações pedagógicas sobre cursos de Psicologia. Trata-se de estudo exploratório, documental, que analisou estatisticamente as taxas de disponibilidade das informações pesquisadas nos sites das respectivas Instituições de Ensino Superior. Os resultados apontam que cursos públicos e privados incorreram em omissão na publicização de informações relevantes, em desacordo com as noções de transparência e accountability e contrariando disposições legais.
\end{abstract}

PALAVRAS-CHAVE: Formação do psicólogo. Currículo. Ensino superior.

\begin{abstract}
Brazilian higher education has expanded in the past 30 years, and Psychology programs have presented a higher growth in enrollment compared to other areas. This article aimed to analyze the online availability of pedagogical data on Psychology courses, such as course description and syllabus. We performed an exploratory, documental research, which analyzed statistics on the availability of such data in websites of Higher Education Institutions. Results indicate that public and private institutions have failed to publish relevant information, in disagreement with the notions of transparency and accountability, in disagreement to Brazilian Law.
\end{abstract}

KEYWORDS: Psychologist education. Curriculum. Higher education. 


\section{Introdução}

O presente trabalho emergiu como desdobramento de um projeto de pesquisa mais amplo, em andamento, cujo objetivo é analisar a abordagem do eixo de Fundamentos Histórico-Epistemológicos dos cursos de graduação em Psicologia brasileira partir de documentos dos cursos, tais como Projetos Pedagógicos de Curso, matrizes curriculares, ementas e bibliografias. Ao buscar nos sites oficiais das Instituições de Educação Superior (IES) tais documentos, deparamo-nos, de imediato, com um problema: muitos deles não estavam disponíveis. Para além do entrave para o projeto de pesquisa original, percebemos que a baixa disponibilidade de informações se constitui como problema importante para estudantes, aspirantes aos cursos e sociedade em geral - embora frequentemente considerado frívolo por docentes e gestores de cursos e IES. Assim, consideramos relevante a publicação dos dados referentes ao grau de disponibilidade dessas informações, analisando-os à luz dos referenciais sobre transparência e accountability de Instituições de Educação Superior.

\section{Relevância da disponibilização de informações pedagógicas no atual cenário da educação supe- rior no Brasil}

A educação superior no Brasil enfrentou acentuadas modificações nos últimos 30 anos. Expandiu-se vigorosamente, diversificou-se, chegou aos interiores do país, incorporou tecnologias de informação e comunicação nas atividades pedagógicas e abriu-se para as camadas sociais mais vulnerabilizadas.

Entre os avanços alcançados, uma das marcas mais celebradas tem sido a massificação. Por meio da expansão dos setores público e privado, observou-se, entre 1995 e 2012, um impressionante salto de 1.759 .703 para 7.037.688 de matrículas em cursos de graduação - um incremento de 299,9\% (Gaspar \& Fernandes, 2014). Não obstante, esta massificação também tem sido alvo de preocupação, haja vista seu acentuado viés de mercantilização (Dias, 2010; Sguissardi, 2015).

Este avanço contrariou o disposto no Plano Nacional de Educação (PNE-2001/2011), em sua determinação de que o setor público sempre mantivesse uma proporção nunca inferior a $40 \%$ do total de matrículas na educação superior (Lei n. 10.172, 2001). Mesmo com a expansão do ensino superior público, por meio do Programa de Apoio a Planos de Reestruturação e Expansão das Universidades Federais (Reuni), em 2015, as matrículas públicas corresponderam apenas a $24 \%$ do total, devido ao intenso crescimento da rede privada (Instituto Nacional de Estudos e Pesquisas Educacionais Anísio Teixeira [Inep], 2016).

Esse crescimento tem se dado, sobretudo, no setor educacional com fins lucrativos, dominado por grandes empresas, muitas delas com capital na bolsa de valores. Tal fenômeno de formação de oligopólios educacionais e mercantilização do ensino tem ampla base na literatura (da qual citamos: Cruz \& Paula, 2018; Chaves, 2010). Assim, embora reconhecendo a existência de instituições privadas com excelente qualidade e sem direcionamento para o mercado ou acumulação de capital, que se configuram como ilhas de excelência e resistência ao processo, observamos que, de forma geral, o Estado não tem sido capaz de contrabalançar o crescimento do empresariado no setor educacional, que tem transformado um direito social em mercadoria.

Nesse cenário, uma das áreas que mais cresceu foi a Psicologia, configurando, em 2017, o sexto curso em número de estudantes (Inep, 2018), totalizando 249.956 matrículas. No entanto, esta ampliação do número de estudantes não está acompanhada do incremento da qualidade de ensino. Ao contrário, aponta-se para uma precarização, compreendida como resultado da incompatibilidade entre lucro e qualidade do ensino (Macedo, Ramos, Souza, Lima, \& Fonseca, 2018; Rudá \& Silva, 2020; Souza, Bastos, \& Barbosa, 2011).

No contexto de massificação precarizada, entendese que a disponibilização de informações pedagógicas, como destaca Zapata (2006), cumpre dois papeis fundamentais: tanto servir como instrumento para avaliação, coordenação e regulação da educação superior, podendo subsidiar políticas públicas, como para a tomada de decisões dos atores envolvidos. Assim, destacamos pelo menos três públicos de especial interesse: aspirantes, comunidade em geral e estudantes regulares.

Para aspirantes, embora sejam vários os fatores associados à escolha de uma IES, entende-se que informações referentes a aspectos pedagógicos dos cursos são de fundamental importância para uma adequada decisão e maximização da experiência formativa (Dill \& Soo, 2004). Nesse sentido, a noção de transparência subsidia as escolhas referentes às 
instituições, programa e percurso acadêmico, à medida que informa quanto ao perfil e qualidade dos programas de ensino; ao desempenho e potencial das instituições; e, ao desempenho geral e potencial dos sistemas de ensino superior (Costes et al., 2010).

Para a comunidade em geral, é importante o acompanhamento da formação de profissionais de nível superior, visto que a finalidade última da Educação é formar pessoas capacitadas para atuar na sociedade. As informações pedagógicas mostram quais são os conteúdos desenvolvidos em cada curso e sob quais perspectivas ou abordagens teóricas, sua articulação - ou desarticulação - com as Diretrizes Curriculares Nacionais, bem como o grau de integração do curso com as demandas políticas e sociais do país e com as necessidades locais e regionais. Conforme Zapata (2006), à medida que determinado sistema de educação superior se massifica e diversifica, como é o caso brasileiro, maior é a necessidade por informação, a qual se apresenta como um imperativo funcional, visto que crucial para assegurar a integração da oferta acadêmica com demandas sociais e o interesse público.

Para estudantes regulares das IES, informações pedagógicas podem facilitar o processo de afiliação (Coulon, 2017). Diante da massificação do ensino superior brasileiro, atualmente o maior problema de estudantes não é acessar o ensino superior, mas permanecer, o que exige - dentre outros requisitos o aprendizado do ofício de estudante: "A mudança mais espetacular que se produz com o ingresso na universidade é a relação dos novos estudantes com as regras e os saberes, uma verdadeira aprendizagem prática que deve ser desenvolvida" (Coulon, 2017, p. 1242).

O processo de afiliação é gradual e se dá de acordo com três fases descritas por Coulon (2017): estranhamento, aprendizagem e afiliação. Os dois primeiros tempos tendem a ser mais dolorosos, pois o estudante ainda está na transição entre seu mundo original e aquele no qual adentra e não domina os códigos institucionais e intelectuais que regem esse novo grupo social. A disponibilização de informações claras a respeito do curso em que ingressaram seria, então, uma estratégia importante para facilitar a afiliação e evitar o fracasso acadêmico. Mesmo quando já afiliados, essas informações são fundamentais para que estudantes tenham visão em perspectiva de sua formação e compreensão de como os componentes curriculares (CCs) se articulam entre si e aos objetivos do curso.
Dessa forma, são importantes o acesso a documentos que descrevam os CCs, com os conteúdos abordados (ementas) e bibliografias, mas também com seus objetivos e metodologias, que costumam ser encontrados nos Planos de Ensino-Aprendizagem. Num plano mais amplo, tais CCs devem se articular em percursos acadêmicos construídos a partir de Matrizes Curriculares (MC). Entretanto, a MC é apenas um dos elementos do curso, e precisa guardar relação com seus objetivos, contexto regional, perfil de egresso, corpo docente, infraestrutura, entre outros; o documento que contém essa articulação é o Projeto Pedagógico de Curso (PPC).

Mais recentemente, pesquisadores na área de educação superior emergiram como um novo público de interesse pelos documentos que contêm informações pedagógicas de cursos superiores, tendo percebido o valor dos PPCs, MCs, ementas e bibliografias como material de pesquisas. Dois exemplos recentes são uma pesquisa sobre a inserção da educação ambiental em currículos de cursos superiores de Direito (Ribeiro \& Ferreira, 2019) e uma pesquisa sobre a inserção da educação especial nos currículos de licenciaturas (Borges, Santos, \& Costa, 2019). Ambos apontaram dificuldades de obter os PPCs nos sites das instituições e lacunas quanto à abordagem de conteúdos obrigatórios por lei nos cursos de graduação.

\section{Transparência e accountability de IES}

Produzir, reunir e disseminar conhecimento são algumas das missões de IES, conforme preconiza a Lei de Diretrizes e Bases da Educação Nacional - LDB (Lei n. 9.394, 1996). Portanto, para além do compromisso com seus estudantes regulares, essas instituições servem à sociedade, que tem o direito e dever de monitorá-las. Para essa finalidade, espera-se que as IES disponibilizem informações capitais do processo educativo.

Essa necessidade por informações tem sido uma tendência mundial, obedecendo a mudanças nos modelos de governança da educação superior, que retiram a centralidade do Estado no que tange ao financiamento, regulação e gestão das políticas educacionais e IES (Jongbloed, Vossensteyn, van Vught, \& Westerheijden, 2018). Em razão de peculiaridades de seus respectivos sistemas de educação superior, cada país enfrenta distintos desafios para o atendimento desta demanda. Não obstante, as noções de transparência e accountability aparecem como denominador comum a qualquer cenário. 
Embora imbricadas, são conceitos relativamente distintos. O termo accountability diz respeito ao complexo sistema que integra avaliação, prestação de contas para a sociedade e responsabilização do agente político (Afonso, 2009). No âmbito da educação superior, refere-se à justificação de valor e qualidade de um sistema aos públicos de interesse, isto é, estudantes, aspirantes às vagas, governo, investidores, sociedade em geral, possibilitando que o público interessado tenha uma participação mais efetiva, permitindo a construção de um quadro de referência para que possam comparar e orientar melhor seus objetivos e decisões (Leveille, 2006).

A transparência, por sua vez, refere-se ao produto de determinado processo que lhe confere qualidade (Costes, Hopbach, Kekäläinen, van ljperen, \& Walsh, 2010). No contexto em questão, conforme definição de Matos (2018), é um atributo das informações próprias do sistema educacional. Assim, será mais transparente determinada informação o quanto for mais completa, amplamente visível, identificável e inferível.

Para Rodrigues (2013), atualmente no Brasil a noção de transparência já se encontra incorporada como uma premissa para o bom funcionamento da Administração Pública como um todo, remetendo a um conjunto de práticas que permitem um controle mais efetivo dos atos do governo. E embora existam desafios quanto ao seu exercício no cotidiano das instituições, existem dispositivos legais, a exemplo da conhecida Lei de Acesso à Informação, que busca assegurar o direito de acesso à informação, tendo como diretrizes, conforme seu Art. $3^{\circ}$ :

I - observância da publicidade como preceito geral e do sigilo como exceção; II - divulgação de informações de interesse público, independentemente de solicitações; III - utilização de meios de comunicação viabilizados pela tecnologia da informação; IV - fomento ao desenvolvimento da cultura de transparência na administração pública; $V$ - desenvolvimento do controle social da administração pública (Lei n. 12.527, 2011, s/p).
Essa lei se aplica a todas as instituições públicas brasileiras, incluindo as de educação superior. Especificamente para as informações pedagógicas, há determinações na LDB (Lei n. 9.394, 1996) que se aplicam a todas as IES, públicas ou privadas, exigindo a publicação no sítio eletrônico de informações referentes ao funcionamento dos cursos: programas dos cursos e demais componentes curriculares, sua duração, requisitos, qualificação dos professores, recursos disponíveis e critérios de avaliação. Tais informações devem ser, conforme a legislação, disponibilizada tanto fisicamente em local visível nas dependências da IES, quanto em página específica na internet no sítio eletrônico oficial da instituição de ensino superior.

Por conta das determinações legais, bem como da missão das instituições de educação superior de disseminar informações, esperar-se-ia das IES uma cultura de transparência, com uso dos recursos de Tecnologia de Informação e Comunicação para manter um diálogo com os públicos de interesse. Pesquisas mostraram que há um esforço incipiente das IES públicas (Röder, 2019; Rodrigues, 2013) e privadas (Hammes, 2018) brasileiras nesse sentido, mas ainda há deficiências na apresentação de informações exigidas pela Lei de Acesso à Informação (Rodrigues, 2013), demonstrativos contábeis (Hammes, 2018), capital intelectual e intangíveis (Rezende, Lott, \& Quintanilha, 2019). O grau em que as IES disponibilizam informações ao público em seus portais na internet é variável e apresentou diferenças quanto à região geográfica no estudo de Rodrigues (2013).

O objetivo deste trabalho é analisar a disponibilidade on-line de informações pedagógicas sobre cursos de Psicologia em sites de Instituições de Ensino Superior da macrorregião Nordeste do Brasil. Como objetivos específicos, pretendemos: 1. descrever a frequência de disponibilização de Projeto Pedagógico de Curso (PPC), Matriz Curricular (MC), Planos de Ensino-Aprendizagem (PEA), ementas e bibliografias dos componentes curriculares nos sites das IES; 2 . comparar tais frequências quanto à categoria administrativa da IES (pública ou privada); 3. analisar geograficamente o grau de disponibilização dessas informações, ao comparar as taxas por estado. 


\section{Metodologia}

Trata-se de estudo quantitativo, de caráter documental - isto é, que usa publicações como fontes primárias. Foram recuperados no sistema e-MEC os registros dos cursos de Psicologia da macrorregião Nordeste do Brasil, no dia $1^{\circ}$ de abril de 2018, tendo como critério de inclusão os cursos em situação ativa, já iniciados e em modalidade de bacharelado. Tratase, portanto, de amostra não probabilística e intencional. A restrição ao curso de Psicologia se deu por este estudo ser um desdobramento de um projeto de pesquisa mais amplo, que analisará PPCs de cursos de Psicologia brasileiros. A opção pela macrorregião Nordeste, por sua vez, se deu pela localização da instituição a que estão afiliados os autores da presente pesquisa e o compromisso da universidade com o território em que se insere, mas há intenção de ampliar a amostra para abranger todos os cursos de Psicologia brasileiros em estudos futuros.

Sete estudantes de graduação devidamente treinados localizaram, entre 13 e 26 de abril de 2019, os sites das IES que ofertavam esses cursos e buscaram as seguintes informações: PPCs, matrizes curriculares, planos de ensino-aprendizagem, ementas e bibliografias, preenchendo uma planilha eletrônica no Microsoft Excel. Dados sobre categoria administrativa das IES foram recuperados do e-MEC.

Adotaram-se os seguintes códigos de preenchimento: 1 = informação disponível integralmente; 2 = informação disponível parcialmente; 3 = informação indisponível. Cada curso foi investigado por dois estudantes, de forma independente e cega, isto é: os pares procuraram as informações nos sites sem se comunicarem. No caso de divergência entre dados coletados, uma terceira opinião, proveniente de um dos docentes autores da presente pesquisa, foi considerada. Foram calculadas taxas de concordância entre pares, que proporcionam maior validade à pesquisa, visto que se evita o viés de subjetividade de pesquisadores ao acessar os sites. As análises de concordância consideraram a proporção, em porcentagem, de respostas idênticas entre pesquisadores.
Em seguida, calcularam-se as estatísticas descritivas (frequências relativas) referentes às taxas de disponibilidade das informações pesquisadas nos sites das Instituições de Ensino Superior, analisadas por estado, categoria administrativa e organização acadêmica das IES. As informações foram analisadas quanto à categoria administrativa das IES, usando-se o qui-quadrado de Pearson para testar as hipóteses de pesquisa de que existiriam associações significativas entre categoria administrativa das IES e a disponibilização das informações: PPC, Matriz Curricular (MC), Planos de Ensino-Aprendizagem (PEA), ementas e bibliografias de cursos de Psicologia.

\section{Resultados e Discussão}

Foram localizados 207 cursos de bacharelado em Psicologia na região Nordeste, conforme consulta ao e-MEC realizada em $1^{\circ}$ de abril de 2019. Destes, 175 correspondiam à modalidade bacharelado e estavam em funcionamento na data da consulta, atendendo aos critérios de inclusão do presente estudo - os cursos restantes não estavam em funcionamento à época da consulta.

No que tange à distribuição geográfica, quase metade dos cursos está concentrada em dois estados: Bahia $(29,7 \%)$ e Ceará $(17,1 \%)$, totalizando $47,4 \%$. Sergipe e Alagoas são os estados com menor oferta do curso, correspondendo a 4,0\% e 4,6\% do total da região Nordeste, respectivamente. Mais da metade dos cursos (52\%) está localizada nas capitais dos estados, sendo 19 destes em Salvador (BA), 18 em Fortaleza (CE), 14 em Recife (PE), 8 em Teresina (PI), 7 em São Luís (MA), Natal (RN) e João Pessoa (PB), 6 em Maceió $(A L)$ e 5 em Aracaju (SE).

Quanto à categoria administrativa, 23 cursos são ofertados por instituições públicas $(13,1 \%)$, tendo em cada estado a presença de uma até cinco destas. O curso de Psicologia é oferecido em cinco IES públicas na Bahia $(21,7 \%)$, quatro na Paraíba $(17,4 \%)$ e três no Ceará (13\%). A Tabela 1 mostra a distribuição dos cursos de Psicologia por estado da região Nordeste e categoria administrativa das IES. 
Tabela 1. Distribuição dos cursos de Psicologia por estado da região Nordeste e categoria administrativa das IES, em número absoluto (N) e porcentagem (\%), no dia $1^{\circ}$ de abril de 2019

\begin{tabular}{|c|c|c|c|c|c|c|c|}
\hline Estado & Pública & & Privada & & Especial & & \\
\hline & $\mathrm{N}$ & $\%$ & $\mathrm{~N}$ & $\%$ & $\mathrm{~N}$ & $\%$ & $\mathrm{~N}$ \\
\hline Alagoas & 2 & 25 & 6 & 75 & - & - & 8 \\
\hline Bahia & 5 & 10,4 & 43 & 89,6 & - & - & 48 \\
\hline Ceará & 3 & 12 & 22 & 88 & - & - & 25 \\
\hline Maranhão & 1 & 10 & 9 & 90 & - & - & 10 \\
\hline Paraíba & 3 & 30 & 7 & 70 & - & - & 10 \\
\hline Pernambuco & 5 & 21,7 & 17 & 73,9 & 1 & 4,3 & 23 \\
\hline Piauí & 2 & 20 & 8 & 80 & - & - & 10 \\
\hline $\begin{array}{l}\text { Rio Grande do } \\
\text { Norte }\end{array}$ & 2 & 20 & 8 & 80 & - & - & 10 \\
\hline Sergipe & 1 & 16 & 5 & 83,3 & - & - & 6 \\
\hline Total & 24 & 16 & 125 & 83,3 & 1 & 0,7 & 150 \\
\hline
\end{tabular}

A Tabela 2 mostra a taxa de concordância entre os pares de estudantes responsáveis pela coleta de informações nos sites das IES quanto à presença ou ausência de informações. Com exceção da matriz curricular, as concordâncias foram superiores a 85\%, sendo, portanto, taxas aceitáveis. As divergências superiores a 10\% na análise da presença de PPC, matriz curricular e ementas nos sites da IES indicam a incipiente transparência das informações publicizadas, sendo, por vezes, necessário aos pesquisadores vasculhar diversas abas e links para encontrar os documentos necessários, quando se faziam presentes. A dificuldade de acesso à informação, mesmo para os pesquisadores treinados, torna-se impeditivo para a efetivação da transparência e suas facetas (direito de saber, de controle e participativo administrativo) (Debbasch, 1990), o que limita a qualidade das informações prestadas pela IES quanto aos cursos ofertados.

Tabela 2. Taxa de concordância, em porcentagem de resultados idênticos, entre os pesquisadores responsáveis pela coleta das informações nos sites das Instituições de Ensino Superior

\begin{tabular}{lc}
\hline \multicolumn{1}{c}{ Informação buscada nos sites das IES } & Taxa de concordância (\%) \\
\hline Projeto Pedagógico de Curso & 89,1 \\
\hline Matriz Curricular & 69,7 \\
\hline Planos de Ensino-Aprendizagem dos CCS & 97,7 \\
\hline Ementas & 85,7 \\
\hline Bibliografias & 94,3 \\
\hline
\end{tabular}

Passando à análise da disponibilidade de informações nos sites, a que esteve presente com maior frequência foi a MC (72,6\%). Outras taxas variaram entre 1,7\% (bibliografias) e 16,0\% (ementas), conforme mostra a Tabela 3. Observou-se, ainda, variação geográfica, conforme mostra a Figura 1. Grande número de cursos disponibilizou em seus sites as matrizes curriculares, mas constatou-se a ausência de outros documentos de maior relevância, como o PPC. Em uma comparação mais ampla, é possível notar que 69,7\% das instituições possuem MC disponível, mas apenas $11,4 \%$ possuem PPC para consulta. 
Tabela 3. Frequências absolutas (N) e relativas (\%) referentes à disponibilidade de informações nos sites dos cursos

\begin{tabular}{lcccccc}
\hline & \multicolumn{2}{c}{ Indisponível } & \multicolumn{2}{c}{ Disponível Integralmente } & \multicolumn{2}{c}{ Disponível parcialmente } \\
& $\mathrm{N}$ & $\%$ & $\mathrm{~N}$ & $\%$ & $\mathrm{~N}$ & $\%$ \\
\hline PPC & 150 & 85,7 & 22 & 12,6 & 3 & 1,7 \\
MC & 36 & 20,6 & 127 & 72,6 & 12 & 6,9 \\
PEA & 171 & 97,7 & 4 & 2,3 & - & - \\
Ementas & 147 & 84,0 & 28 & 16 & - & - \\
Bibliografias & 172 & 98,3 & 3 & 1,7 & - & - \\
\hline
\end{tabular}

Algumas discrepâncias entre as taxas de disponibilização de PPC e MC por estado foram bastantes perceptíveis. No Piauí, nenhum curso disponibilizou o PPC, enquanto em Alagoas (25,0\%) e no Rio Grande do Norte $(23,1 \%)$, tivemos as maiores taxas de disponibilização. A menor taxa de disponibilização de MCs ocorreu no Maranhão $(27,3 \%)$, enquanto no Ceará, chegaram a $90,0 \%$. A observação das estatísticas descritivas permite inferir que fatores culturais relacionados ao uso da internet e estratégias de marketing no mundo digital podem ter levado às disparidades geográficas. Diferenças entre estados e macrorregiões quanto ao grau de transparência em sites de IES públicas já foram constatadas em estudo anterior (Rodrigues, 2013).

O que se manteve constante nos estados e categorias administrativas foi a indisponibilidade de PEAs e das bibliografias dos cursos. PEAs foram disponibilizados apenas por cursos na Bahia (dois em um total de 52), Ceará (um de 29) e Pernambuco (um de 26). Apenas no estado da Bahia houve cursos (dois de 52) que disponibilizaram bibliografias.

Figura 1. Taxas, em porcentagem, de disponibilidade das informações nos sites das Instituições de Ensino Superior: PPC, matriz curricular, planos de ensino-aprendizagem dos CCs, ementas e bibliografias, em porcentagem do total de cursos pesquisados da região Nordeste.

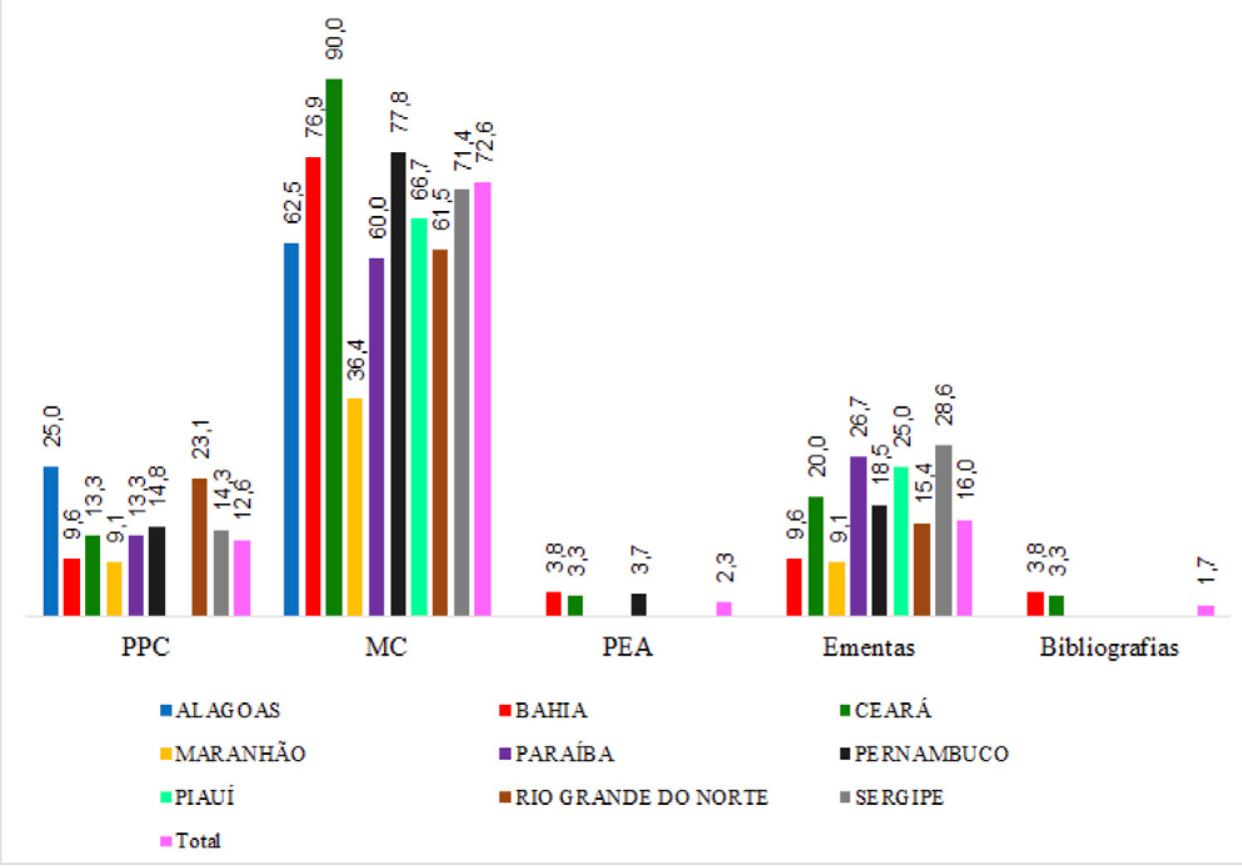

${ }^{1}$ As associações não foram testadas por meio de análises estatísticas inferenciais, pois o baixo número de cursos em alguns estados levaria a violação em pressupostos do teste de qui-quadrado de Pearson. 
Foram analisadas as associações entre categoria administrativa das IES que ofertam os cursos e disponibilidade de informações nos sites institucionais². Observou-se que mais da metade dos cursos de IES públicas disponibilizaram os PPCs, enquanto apenas $6,4 \%$ das privadas o fizeram (Tabela 4). Essa diferença foi estatisticamente significativa no teste de qui-quadrado de Pearson ( $\chi_{\_}{ }^{\wedge} 22=37,943, p<0,001$ ). Quanto à $M C$, a taxa de disponibilização em IES privadas $(75,2 \%)$ foi maior que nas públicas $(62,5 \%)$, mas a diferença não foi estatisticamente significativa $\left(\chi \_1 \wedge 2=1,654, p=0,198\right)$. Não foram testadas as associações entre categoria administrativa e a disponibilidade de PEAs, ementas e bibliografias, pois a baixa frequência de respostas positivas violaria pressupostos do teste.

Tabela 4. Disponibilidade de informações acadêmicas por categoria administrativa da IES que oferta o curso: frequências absolutas (N) e relativas (\%)

\begin{tabular}{lcccc}
\hline & Pública & \multicolumn{2}{c}{ Privada } & \\
PPC & $\mathrm{N}$ & $\%$ & $\mathrm{~N}$ & $\%$ \\
MC & 13 & 54,2 & 8 & 6,4 \\
PEA & 15 & 62,5 & 94 & 75,2 \\
Ementas & 1 & 4,2 & 3 & 2,4 \\
Bibliografias & 4 & 16,7 & 19 & 15,2 \\
\hline
\end{tabular}

Foi notável, portanto, a omissão de informações pedagógicas relevantes para os stakeholders: estudantes do curso, aspirantes ao curso e sociedade em geral, tanto em cursos ofertados por IES públicas, quanto nos de IES privadas. Observou-se, portanto, que a cultura de transparência e accountability está longe de ser estabelecida no Brasil no que diz respeito a informações relativas a uma das atividades fim das IES: o ensino em nível de graduação.

Esse resultado também indica o descumprimento da Lei de Diretrizes e Bases da Educação Nacional, que determina que as IES devem disponibilizar em seus sites e em toda propaganda eletrônica institucional, mediante link para os sites, "os programas dos cursos e demais componentes curriculares, sua duração, requisitos, qualificação dos professores, recursos disponíveis e critérios de avaliação" (Lei n. 9.394, 1996). Pode-se inferir que há simultaneamente um descumprimento da lei e ausência de fiscalização quanto ao seu cumprimento.

Os motivos que levam as IES a não disponibilizar as informações preconizadas pela LDB nos seus sites são desconhecidos, mas algumas suposições são: desconhecimento da lei, desorganização e exagerada burocracia institucional, ou a deliberada intenção de que determinadas informações não sejam conhecidas, evitando-se visibilidade para a baixa qualidade pedagógica e, portanto, a possibilidade de fiscalização, o que contraria completamente a noção de transparência e accountability.

As diferenças entre IES públicas e privadas quanto à taxa de disponibilização de PPCs, mas não de MCs, merece uma análise cuidadosa. Num contexto mercadológico, consideramos que as MCs são atrativas para aspirantes ao curso. São de fácil visualização e, no senso comum, a matriz curricular costuma ser tomada como a formação global - embora esta seja uma falácia, visto que a formação apresenta dimensões muito mais amplas e diversas do que a estrutura curricular - ou seja, uma sistematização de CCs ao longo dos períodos letivos (Rudá, Coutinho, \& Almeida-Filho, 2019). Deste modo, especula-se que funcionem mais como informações descritivas de um produto a ser adquirido do que acadêmicas, propriamente, ao configurarem elementos distintivos para a escolha da IES (Dill \& Soo, 2004).

\footnotetext{
2 Para viabilizar essa análise, devido à baixa frequência de informações parcialmente disponíveis, estas foram somadas às informações indisponíveis, criando-se uma tabela de contingência $2 \times 2$.
} 
As IES públicas, por sua vez, não teriam a necessidade de captar estudantes, visto que são tradicionalmente mais demandadas no Brasil. Desta forma, optam por disponibilizar os PPCs, que - ao menos em tese - são um documento único que contém as informações necessárias, embora não necessariamente organizadas de uma forma que facilite sua localização.

Cabe ressaltar que foi notável, na busca pelas informações, que os sites das IES privadas são repletos de publicidade objetivando obter mais alunos. São enfatizados, em geral, aspectos relativos às facilidades de realizar os cursos, como flexibilidade de horários e formas de pagamento, bem como aspectos atrativos do mercado de trabalho. Informações pedagógicas, entretanto, são difíceis de localizar, mesmo quando existentes. Em alguns sites, explicitava-se que as informações estariam disponíveis conforme demanda aos coordenadores do curso, ou exigia-se o preenchimento de formulários com campos obrigatórios referentes a dados pessoais, e-mail e telefone, configurando uma estratégia agressiva de captação de estudantes.

Estudos anteriores que buscaram informações pedagógicas de outros cursos e regiões também apontaram a sua ausência nos sites das IES, ou até mesmo ausência de resposta de seus representantes quando os documentos foram solicitados. Essa constatação ocorreu em investigações sobre cursos de Direito da Região Metropolitana do Rio de Janeiro (Ribeiro \& Ferreira, 2019), licenciatura em música (Mateiro, 2014) ou nutrição (Recine, Sugai, Monteiro, Rizzolo, \& Fagundes, 2014) em todo o país. A convergência de resultados corrobora a nossa inferência de que provavelmente não se trata de problema isolado dos cursos de Psicologia do Nordeste do Brasil.

A ampliação da coleta de dados prevê entrar em contato com as IES para solicitar a disponibilização das informações ausentes, para fins de pesquisa. Acionaremos as coordenações de curso, sempre que possível; as pró-reitorias de graduação; e, no caso das IES públicas, o Sistema Eletrônico do Serviço de Informações ao Cidadão (e-SIC) (https://esic.cgu.gov. br/sistema/site/index.aspx, acesso em 15 dez. 2019).
Essa etapa do trabalho viabilizará a construção de dados sobre a disponibilidade dessas informações mediante solicitação, isto é, a transparência passiva.

\section{Considerações Finais}

Embora a disponibilização de informações pedagógicas nos sites das IES seja uma obrigação preconizada pela LDB (Lei n. 9.394, 1996), a lei vem sendo descumprida pelas IES do Nordeste do Brasil, o que prejudica a transparência e a accountability. $O$ fenômeno ocorre de simultaneamente nas IES públicas e privadas, embora com alguma diferença quanto à preferência pelo tipo de informação compartilhada, que nas IES privadas, tende a ter características mais alinhadas com estratégias de marketing. Portanto, são necessárias medidas de criação de uma cultura de disponibilização de informações, independentemente de solicitações (transparência ativa), bem como uma melhor fiscalização.

As informações sobre cursos são fundamentais para que se obtenha controle social sobre a formação em nível superior, tanto no âmbito público quanto no privado, sobretudo no atual cenário de precarização, massificação e mercantilização; para estudantes regulares do ensino superior, e baseando-nos no trabaIho de Coulon (2017), supomos que tais informações, muito mais que um mero detalhe, são um recurso para facilitar a superação da fase de estranhamento, com a assimilação das regras e códigos desse novo grupo social e consequente afiliação dos estudantes à IES, o que poderia contribuir para a sua permanência.

Portanto, seria necessária fiscalização mais rigorosa por conta do órgão regulador - no caso, o MEC - quanto ao cumprimento desse aspecto da LDB (Lei n. 9.394, 1996). Uma alternativa para a ampliação da visibilidade de informações pedagógicas poderia ser a sua publicação no e-MEC, visto que, com exceção dos Planos de Ensino-Aprendizagem, as demais informações são solicitadas às IES nos atos de autorização e reconhecimento de cursos. Essa atitude estaria de acordo com a da Lei de Acesso à Informação (Lei n. 12.527, 2011) em sua diretriz de "divulgação de informações de interesse público, independentemente de solicitações". 
Uma limitação da presente pesquisa foi a restrição aos cursos de Psicologia e à região Nordeste, escolhidos intencionalmente. Não encontramos motivos para supor que outros cursos de graduação tenham níveis diferentes de disponibilização de informações pedagógicas. No entanto, para evitar vieses e permitir comparações, seria interessante incluí-los em pesquisas futuras. Quanto à distribuição geográfica, dado que as taxas de publicização de informações variaram entre estados do Nordeste, é possível supor que haverá diferença, também, entre macrorregiões. Essa hipótese poderá ser investigada em trabalho futuro, visto que o projeto em que se insere esta coleta de dados incluirá todos os cursos de Psicologia brasileiros.

Consideramos que, a despeito de tais limitações, a presente pesquisa é relevante por sua originalidade e pelo rigor metodológico ao realizar a coleta de dados por pesquisadores independentes e cegos, evitando vieses de subjetividade nessa etapa. Os resultados evidenciaram a incipiência da cultura de transparência e accountability em IES brasileiras, visto que até mesmo informações fundamentais sobre as características dos cursos ofertados - e referentes, portanto, à atividade fim das IES - estão indisponíveis na internet.

Futuros estudos poderão ampliar a análise sobre disponibilidade de informações pedagógicas de cursos de graduação geograficamente, ao abarcar outras regiões do Brasil; e poderão considerar o grau de disponibilização de documentos sob demanda, isto é, quando consultadas as coordenações de curso e gestores das IES. Também é possível investigar, por meio de entrevistas ou questionários, o impacto da disponibilidade ou indisponibilidade de informações pedagógicas na compreensão que docentes e estudantes têm do curso, de forma abrangente, envolvendo a articulação entre conteúdos, bibliografias, componentes curriculares, possíveis percursos acadêmicos e os objetivos e perfil de egressos do curso.

\section{Contribuições dos autores}

Silva, G. A. e Martins, V. D. participaram da concepção, delineamento, coleta e interpretação dos dados, análise estatística dos dados da pesquisa, interpretação dos resultados, e redação. Rudá, C. participou da concepção, delineamento, coleta e interpretação dos dados, interpretação dos resultados e redação do artigo científico. Borges, J. P. L., Alves, J. P. R. e Soares, T. L. F. S. participaram da coleta e interpretação dos dados, interpretação dos resultados, e redação.

\section{Conflitos de interesses}

Nenhum conflito financeiro, legal ou político envolvendo terceiros (governo, empresas e fundações privadas, etc.) foi declarado para nenhum aspecto do trabalho submetido (incluindo, mas não se limitando a subvenções e financiamentos, participação em conselho consultivo, desenho de estudo, preparação de manuscrito, análise estatística, etc.).

\section{Referências}

Afonso, A. J. (2009). Nem tudo o que conta em educação é mensurável ou comparável: crítica à accountability baseada em testes estandardizados e rankings escolares. Revista Lusófona de Educação, 13(13), 13-29. Recuperado de http://revistas.ulusofona.pt/index.php/rleducacao/article/ view/545

Borges, W. F., Santos, C. S., \& Costa, M. P. R. (2019). Educação especial e formação de professores: uma análise dos projetos pedagógicos de curso (PPC). RIAEE - Revista Ibero-Americana de Estudos em Educação, 14(1), 138156. Recuperado de https://periodicos.fclar.unesp.br/ iberoamericana/article/view/11267. doi: 10.21723/riaee. $\underline{\mathrm{v} 14 \mathrm{i} 1.11067}$

Lei n. 9.394, de 20 de dezembro de 1996. Estabelece as diretrizes e bases da educação nacional. Recuperado de http://www. planalto.gov.br/ccivil_03/LEIS/L9394.htm

Lei n. 10.172, de 9 de janeiro de 2001. Aprova o Plano Nacional de Educação e dá outras providências. Recuperado de http:// www.planalto.gov.br/ccivil_03/leis/leis_2001/l10172.htm

Lei n. 12.527, de 18 de novembro de 2011. Regula o acesso a informações previsto no inciso XXXIII do art. $5^{\circ}$, no inciso II do $\S 3^{\circ}$ do art. 37 e no $\S 2^{\circ}$ do art. 216 da Constituição Federal; altera a Lei $n^{\circ} 8.112$, de 11 de dezembro de 1990; revoga a Lei $n^{\circ} 11.111$, de 5 de maio de 2005, e dispositivos da Lei $n^{\circ} 8.159$, de 8 de janeiro de 1991; e dá outras providências. Recuperado de http://www.planalto. gov.br/ccivil_03/_ato2011-2014/2011/lei//12527.htm

Chaves, V. L. J. (2010). Expansão da privatização/mercantilização do ensino superior Brasileiro: a formação dos oligopólios. Educação \& Sociedade, 31(111), 481-500. Recuperado de https://www.scielo.br/scielo.php?pid=S0101$73302010000200010 \&$ script=sci_abstract\&tlng=pt. doi: 10.1590/S0101-73302010000200010

Costes, N., Hopbach, A., Kekäläinen, H., van ljperen, R., \& Walsh, P. (2010). Quality assurance and transparency tools [Workshop Report]. Helsinki: European Association for Quality Assurance in Higher Education. Recuperado de https:// files.eric.ed.gov/fulltext/ED541662.pdf 
Coulon, A. (2017). O ofício de estudante: a entrada na vida universitária. Educação e Pesquisa, 43(4), 1239-1250. Recuperado de https://www.scielo. br/scielo.php?script=sci_abstract\&pid=S151797022017000401239\&lng=pt\&nrm=iso. doi: $10.1590 /$ s1517-9702201710167954

Cruz, A. G., \& Paula, M. F. C. (2018). Capital e Poder a serviço da Globalização: os oligopólios da educação superior privada no Brasil. Avaliação: Revista da Avaliação da Educação Superior, 23(3), 848-868. Recuperado de https://www. scielo.br/scielo.php?script=sci_abstract\&pid=S141440772018000300848\&lng=en\&nrm=iso\&tlng=pt. doi: $10.1590 / s 1414-40772018000300016$

Debbasch, P. (1990). La transparence administrative en Europe. Paris: CNRS.

Dias Sobrinho, J. (2010). Avaliação e transformações da educação superior brasileira (1995-2009): do Provão ao SINAES. Revista da Avaliação da Educação Superior, 15(1), 195-224. Recuperado de http://www.scielo.br/scielo.php?script=sci_ arttext\&pid=S1414-40772010000100011\&lng=en\&nrm=iso \&tlng=pt. doi: $10.1590 / \$ 1414-40772010000100011$

Dill D. D., \& Soo M. (2004) Transparency and Quality in Higher Education Markets. In P. Teixeira, B. Jongbloed, D. Dill, \& A. Amaral. (Eds). Markets in Higer Education. Higher Education Dynamics (6, pp. 61-85). Londres: Springer.

Gaspar, R. F., \& Fernandes, T. C. (2014). Mercantilização e oligopolização no ensino superior privado. Educação \& Realidade, 39(3), 945-966. Recuperado de http://www. scielo.br/scielo.php?script=sci_arttext\&pid=S217562362014000300017\&lng=en\&nrm=iso. doi: $10.1590 /$ S2175-62362014000300017

Hammes, N. L. (2018). Fatores determinantes do nível de transparência de mantenedoras de instituições privadas de ensino superior no Brasil (Dissertação de Mestrado). Universidade do Vale do Rio dos Sinos, São Leopoldo, RS, Brasil. Recuperado de http://www.repositorio.jesuita.org. br/handle/UNISINOS/7280

Instituto Nacional de Estudos e Pesquisas Educacionais Anísio Teixeira (2016). Sinopse Estatística da Educação Superior 2015 [Planilha do Microsoft Excel]. Brasília: Instituto Nacional de Estudos e Pesquisas Educacionais Anísio Teixeira. Recuperado de http://download.inep.gov.br/ informacoes_estatisticas/sinopses_estatisticas/sinopses_ educacao_superior/sinopse_educacao_superior_2015.zip

Instituto Nacional de Estudos e Pesquisas Educacionais Anísio Teixeira (2018). Sinopse Estatística da Educação Superior 2017 [Planilha do Microsoft Excel]. Brasília: Instituto Nacional de Estudos e Pesquisas Educacionais Anísio Teixeira. Recuperado de http://download.inep.gov.br/ informacoes_estatisticas/sinopses_estatisticas/sinopses_ educacao_superior/sinopse_educacao_superior_2017.zip
Jongbloed, B., Vossensteyn, H., van Vught, F., \& Westerheijden, D. F. (2018). Higher education: the emergence of a new perspective on higher education governance. In A. Curaj, L. Deca, R. Pricopie. (Eds.). European higher education area: the impact of past and future policies (pp. 441-454): Springer.

Leveille, D. E. (2006). Accountability in higher education: a public agenda for trust and cultural change, research \& occasional papers [Internet]. Research \& Occasional Paper Series: a report. Recuperado de http://files.eric.ed.gov/fulltext/ ED503070.pdf

Macedo, J. P., Ramos, B. B., Souza, C. J., Lima, M. S. S., \& Fonseca, K. P. B. C. (2018). Formação em Psicologia e oligopolização do ensino superior no Brasil. Estudos de Psicologia, 23(1), 46-56. Recuperado de http://pepsic.bvsalud.org/scielo. php?script=sci_arttext\&pid=S1413-294X2018000100006. doi: $\underline{10.22491 / 1678-4669.20180006}$

Mateiro, T. (2014). Uma análise de projetos pedagógicos de licenciatura em música. Revista da ABEM, 17(22), 57-66. Recuperado de http://abemeducacaomusical.com.br/ revistas/revistaabem/index.php/revistaabem/article/ view/226/158

Matos, A. S. (2018). Estudo da transparência ativa de uma Instituição de Ensino Superior (Dissertação de Mestrado). Universidade Federal da Grande Dourados, Dourados, MT, Brasil. Recuperado de http://repositorio.ufgd.edu.br/jspui/ bitstream/prefix/977/1/AdilsondaSilvaMatos.pdf

Recine, E., Sugai, A., Monteiro, R. A., Rizzolo, A., \& Fagundes, A. (2014). Saúde coletiva nos cursos de nutrição: análise de projetos polítco-pedagógicos e planos de ensino. Revista de Nutrição, 27(6), 747-760. Recuperado de https://www.scielo.br/scielo.php?pid=S1415-

52732014000600747\&script=sci_abstract\&tlng=pt. doi: 10.1590/1415-52732014000600009

Ribeiro, E. F. S., \& Ferreira, M. S. (2019). Inserção da educação ambiental nos projetos pedagógicos dos cursos de direito: uma análise na região metropolitana do Rio de Janeiro. Revista Brasileira de Educação Ambiental, 14(1), 316-338. Recuperado de https://periodicos.unifesp.br/index.php/ revbea/article/view/2719. doi: 10.34024/revbea.2019. v14.2719

Rezende, J. F. C., Lott, A. C. O., \& Quintanilha, G. (2019). Estudo comparativo sobre a divulgação de intangíveis e capital intelectual em Instituições de Ensino Superior no Brasil e na Áustria. Administração: Ensino e Pesquisa, 20(2), 249285. Recuperado de https://raep.emnuvens.com.br/raep/ article/view/1201. doi: 10.13058/raep.2019.v20n2.1201 
Röder, N. G. J. M. (2019). Governo eletrônico e aberto: acesso à informação e participação digital em Instituições Federais de Ensino Superior (IFES). (Dissertação de Mestrado). Universidade Tecnológica Federal do Paraná, Curitiba, PR, Brasil. Recuperado de http://repositorio.utfpr.edu.br/jspui/ bitstream/1/4131/1/CT_PROFIAP_M_R\%c3\%b6der\%2c\%20 Nathalie\%20Gabrielle\%20Jun\%20Matsumoto_2019.pdf

Rudá, C., \& Silva, G. A. (2020). Formação do psicólogo na Bahia: uma análise a partir do ENADE 2015. Revista do Centro de Educação (UFSM), 45, 1-25. Recuperado de https:// periodicos.ufsm.br/reveducacao/article/view/34755. doi: $10.5902 / 1984644434755$

Rudá, C., Coutinho, D., \& Almeida-Filho, N. (2019). Formação em Psicologia: uma análise curricular de cursos de graduação no Brasil. E-curriculum, 17(2), 419-440. Recuperado de https://revistas.pucsp.br/curriculum/article/ view/38570/29022. doi: 10.23925/1809-3876.2019v17i 2p419-440

Rodrigues, G. M. (2013). Indicadores de "transparência ativa" em instituições públicas: análise dos portais de universidades públicas federais. Liinc em Revista, 9(2), 423-438. Recuperado de http://revista.ibict.br/liinc/article/ view/3474. doi: 10.18617/liinc.v9i2.616

Sguissardi, V. (2015). Educação superior no Brasil: democratização ou massificação mercantil? Educação \& Sociedade, 36(133), 867-889. Recuperado de https://www.redalyc. org/pdf/873/87343512002.pdf. doi: 10.1590/ES010173302015155688

Souza, M. P. R, Bastos, A. V., \& Barbosa, D. R. (2011). Formação básica e profissional do psicólogo: análise do desempenho dos estudantes no Enade-2006. Avaliação Psicológica, 10(3), 295-312. Recuperado de https://www.redalyc.org/ pdf/3350/335027287005.pdf

Zapata, G. (2006). Información en educación superior. Revista Calidad en la Educación, 24, 199-213. Recuperado de https://www.calidadenlaeducacion.cl/index.php/rce/ article/view/275. doi: 10.31619/caledu.n24.275 